\title{
Videogrammetric Measurement Techniques for High Speed Wind Tunnel Testing
}

\section{Zhang Zhengyu}

State Key Laboratory of Aerodynamics, high speed Aerodynamics institute, China Aerodynamics Research and Development Center (CARDC) ,Mianyang 621000

People's Republic of China

\section{Huang Xuhui}

China Aerodynamics Research and Development Center (CARDC) ,Mianyang 621000, People's Republic of China

\author{
Zhou Run \\ China Aerodynamics Research and Development \\ Center (CARDC) ,Mianyang 621000, People's Republic \\ of China
}

Yin Jiang

China Aerodynamics Research and Development Center (CARDC) ,Mianyang 621000, People's Republic of China

\begin{abstract}
Videogrammetric measurement is a research focus for the organizations of wind tunnel test, and it has no special requirements on the test model. Its key techniques for the test environment of the high speed wind tunnel are introduced in this paper, including the solution of exterior parameters with big-angle large overlap, the algorithm of image processing for extracting marked point, the method of camera calibration and wave-front distortion field measurement. The great requirements and application prospects of videogrammetric measurement in wind tunnel fine testing have been demonstrated by several practice experiments, such as measurement of model's angle of attack, measurement of test model's dynamic deformations and wave-front distortion field in high speed wind tunnels.
\end{abstract}

Keywords-videogrammetric measurement; aero-optics; wind tunnel test;

\section{INTRODUCTION}

The fine design of modern aircraft demands the more and more precise data of wind tunnel test, therefore, the corrections on elastic angle and elastic deformation of the test models must be taken into consideration[1-2], which require to measure the attitude and deformation of test model rather than the attitude and position of supporter used to fix the test model [4-9]. In addition, for all kinds of optical systems onboard high-speed aircraft[3], it is necessary to measure and correct aero-optics effects, such as detection systems of photoelectric imaging and the optical communication system etc, which need urgently to quantify wavefront distortion in large wind tunnel with high spatial resolution to generate the correction method.

Therefore, the videogrammetric techniques[1-11] which uses CCD images and photogrammetric techniques are presented for high speed wind tunnel testing; the several practice experiments in the CARDC transonic and supersonic wind tunnels are also introduced.

\section{VIDEOGRAMMETRIC MEASUREMENT PRINCIPLE}

Collinear equations describe the principle of the videogrammetry[1-2], their expression is

$$
\left\{\begin{array}{l}
x+f \frac{a_{1}\left(X-X_{s}\right)+b_{1}\left(Y-Y_{s}\right)+c_{1}\left(Z-Z_{s}\right)}{a_{3}\left(X-X_{S}\right)+b_{3}\left(Y-Y_{s}\right)+c_{3}\left(Z-Z_{s}\right)}+x_{u}=x_{0} \\
y+f \frac{a_{2}\left(X-X_{s}\right)+b_{2}\left(Y-Y_{s}\right)+c_{2}\left(Z-Z_{s}\right)}{a_{3}\left(X-X_{S}\right)+b_{3}\left(Y-Y_{s}\right)+c_{3}\left(Z-Z_{s}\right)}+y_{u}=y_{0}
\end{array}\right.
$$

where(a1, a2, a3, b1, b2, b3, c1, c2, c3) are the nine elements of rotation matrix $R$ determined by the attitude ( $\varphi$, $\omega, \kappa)$ of camera; $(\mathrm{x} 0, \mathrm{y} 0)$ are the center coordinates of camera image plane; and $f$ is the camera focal length; $x_{u \text { and }} y_{u}$ are the distortion parameters; (Xs, Ys, Zs) are coordinates of camera center in $3 \mathrm{D}$ coordinate system; (x, $\mathrm{y})$ and $(\mathrm{X}, \mathrm{Y}, \mathrm{Z})$ are the coordinates of a measuring points in $2 \mathrm{D}$ image and $3 \mathrm{D}$ coordinate system respectively. When the camera parameters as well as the $2 \mathrm{D}$ image coordinates of the points are known, their 3D coordinates can be computed by the equations(1).

Coplanar equations [10] describe the homologous points on the images taken by the different view angles are coplanar. Given two pictures $I_{A}$ and $I_{B}$, the homologous point set is $P$, where $\forall p_{i} \in P, p_{i}=\left(p_{i}^{A}, p_{i}^{B}\right)$; $S_{A} u_{1} v_{1} w_{1}$ and $S_{B} u_{2} v_{2} w_{2}$ are $3 \mathrm{D}$ image coordinate systems of $I_{A}$ and $I_{B}$ respectively; 3D image coordinates of $p_{i}^{A}$ and $p_{i}^{B}$ in $S_{A} u_{1} v_{1} w_{1}$ and $S_{B} u_{2} v_{2} w_{2}$ are $\left(u_{1}, v_{1}, w_{1}\right)$ and $\left(u_{2}, v_{2}, w_{2}\right)$ respectively; $S_{1}$ and $S_{2}$ are origins of coordinate of $S_{1} u_{1} v_{1} w_{1}$ and $S_{2} u_{2} v_{2} w_{2}$ 
respectively. The coordinates of $S_{2}$ in $S_{1} u_{1} v_{1} w_{1}$ is $\left(b_{x}, b_{y}, b_{z}\right)$, then coplanar equations of $p_{i}^{A}$ and $p_{i}^{B}$ are

$$
F\left(p_{i}\right)=\left|\begin{array}{ccc}
b_{x} & b_{y} & b_{z} \\
x_{1}^{A}+x_{u} & y_{1}^{A}+y_{u} & -f \\
u_{2} & v_{2} & w_{2}
\end{array}\right|=0
$$

where

$$
\left[\begin{array}{c}
u_{2} \\
v_{2} \\
w_{2}
\end{array}\right]=R_{2} \times\left[\begin{array}{c}
x_{2}^{B}+x_{u} \\
y_{2}^{B}+y_{u} \\
-f
\end{array}\right]
$$

$\left(x_{1}^{A}, y_{1}^{A}\right)$ in equation(2) and $\left(x_{2}^{B}, y_{2}^{B}\right)$ in equation(3)

are 2D image coordinates of $p_{i}^{A}$ and $p_{i}^{B}$ respectively; $R_{2}$ is the rotation matrix from $S_{2} u_{2} v_{2} w_{2}$ to $S_{A} u_{1} v_{1} w_{1}$

\section{KEY TECHNIQUES}

\section{A. Camera calibration}

Due to the limits of the space and observation windows' positions for wind tunnel test section, the CCD images taken by big rotation angles and large overlap of multi-cameras are inevitably for videogrammetric measurement in wind tunnel tests, especially for high speed wind tunnels, their vibrations as well as aerodynamic noises are larger in the testing, high-precision exterior parameters and interior parameters is needed [2-9]. The exterior parameters can be easily obtained by linear and small-angle model for the traditional (aviation) photogrammetry(it is nearly vertical photography). But for big rotation angles and large overlap of multi-cameras, the nonlinear characteristics of collinear equation must be taken into consideration to obtain the precision exterior parameters, which are basis to accurately get the 3D coordinates. The distortion models include radial distortion, eccentric aberration and thin prism distortion [10,12], shown as follow

$$
\begin{aligned}
& \left\{\begin{array}{l}
x_{u}=\delta x_{r}+\delta x_{d}+\delta x_{p} \\
y_{u}=\delta y_{r}+\delta y_{d}+\delta y_{p}
\end{array}\right. \\
& \text { where } \\
& \left\{\begin{array}{l}
\delta x_{r}=x\left[k_{1}\left(x^{2}+y^{2}\right)+k_{2}\left(x^{2}+y^{2}\right)^{2}\right] \\
\delta y_{r}=y\left[k_{1}\left(x^{2}+y^{2}\right)+k_{2}\left(x^{2}+y^{2}\right)^{2}\right]
\end{array}\right. \\
& \left\{\begin{array}{l}
\delta x_{d}=p_{1} x\left(3 x^{2}+y^{2}\right)+2 p_{2} x y \\
\delta y_{d}=2 p_{1} x y+p_{2} x\left(x^{2}+3 y^{2}\right)
\end{array}\right. \\
& \left\{\begin{array}{l}
\delta x_{p}=s_{1}\left(x^{2}+y^{2}\right) \\
\delta y_{p}=s_{2}\left(x^{2}+y^{2}\right)
\end{array}\right.
\end{aligned}
$$

Because $b_{x}$ describes the scale of the relative orientation, as long as the total number $m$ of $P$ more than 13, the five relative orientation elements $\left.b_{y}, b_{z}, \varphi, \omega, \kappa\right)$, the six distortion parameters $\left(k_{1}, k_{2}\right.$, $\left.p_{1}, p_{2}, s_{1}, s_{2}\right)$ and $\left(x_{0}, y_{0}\right)$ can be calculated by equation(2). The generalized inverse method of least square solution is used to solve equation (2). Let a vector $X=\left(b_{y}, b_{z}, \varphi, \omega, \kappa, k_{1}, k_{2}, p_{1}\right.$ $\left.p_{2}, s_{1}, s_{2}, x_{0}, y_{0}\right)$, then the Jacobi matrix of equation (2) is shown as follow

$$
f(X)=\left[\begin{array}{cccc}
\frac{\partial F\left(p_{0}\right)}{\partial b_{y}} & \frac{\partial F\left(p_{0}\right)}{\partial b_{z}} & \Lambda & \frac{\partial F\left(p_{0}\right)}{\partial y_{0}} \\
\frac{\partial F\left(p_{1}\right)}{\partial b_{y}} & \frac{\partial F\left(p_{1}\right)}{\partial b_{z}} & \Lambda & \frac{\partial F\left(p_{1}\right)}{\partial y_{0}} \\
\Lambda & \Lambda & \Lambda & \Lambda \\
\frac{\partial F\left(p_{m}\right)}{\partial b_{y}} & \frac{\partial F\left(p_{m}\right)}{\partial b_{z}} & \Lambda & \frac{\partial F\left(p_{m}\right)}{\partial y_{0}}
\end{array}\right]
$$

$$
\left\{\begin{array}{c}
X^{(k+1)}=X^{(k)}-\alpha_{k} Z^{(k)} \\
A^{(k)} Z^{(k)}=\left(F\left(p_{0}\right)^{(k)}, F\left(p_{1}\right)^{(k)}, \Lambda, F\left(p_{m-1}\right)^{(k)}\right)^{T}
\end{array}\right.
$$

where $A^{(k)}$ is the Jacobin matrix of the $X^{(k)}, \alpha_{k}$ is value which makes

$$
\sum_{i=0}^{m-1}\left(F\left(p_{i}\right)^{(k)}\right)^{2}
$$

get minimum value, the rational extremum method ${ }^{[10]}$ is used to compute $\alpha_{k}$.

\section{B. Image process of mark points.}

The artificial coded points are pasted on surface of the test model, to produce high contrast image of mark points. The coded points use the concentric ring to encoding and the circle point located in the center to determine their location. Therefore, from the differences of concentric ring around the center point, the homologous coded points can be automatically identified[1-2].The Canny edge detector is used to generate contours of coded points and the other points. The median filtering method is employed to leach the noise in images, and the positioning precision (range from 0.01 to 0.03 pixels) can be obtained using gray center of gravity method, least square fitting method or centerweighted gray et al.

\section{Aero-optics wavefront measurement.}

Following the principle of aero-optics wavefront distortion and ray trace, the refraction of a beam is caused by the disturbance flow. The deviation angle

$$
\varepsilon=\int_{s} \nabla n d s
$$


background points.

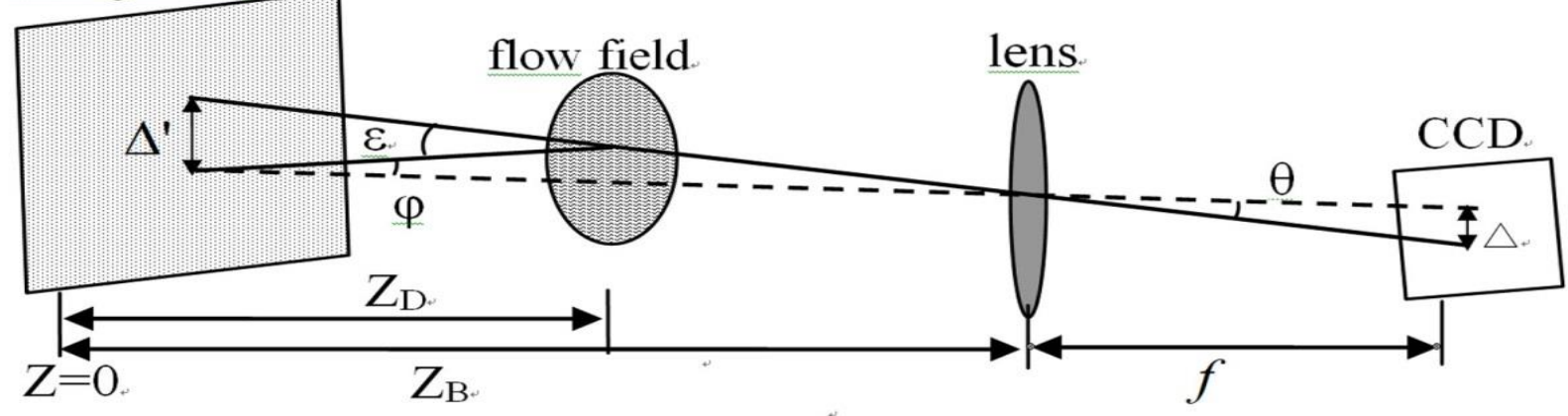

Figure 1. Principle of measurement

where $n$ is the index-of-refraction, optical path length (OPL)

$$
\phi=\int_{s} n d s
$$

As shown in the fig .1, $\varepsilon$ is small in aero-optics application, $d s \approx d z$ is reasonable, thus optical path difference (OPD) can be calculated by

$$
\hat{\phi}=\phi-\bar{\phi}=2 \Delta Z_{D} \varepsilon
$$

where $\bar{\phi}$ is the OPL of the beam crossing the flow field without disturbances, $\Delta Z_{D}$ is the half of length of flow disturbances in $\mathrm{Z}$ direction. In the Fig .1, because of $\Delta Z_{D}<<Z_{D}$, according to projective geometry, we can get

$$
\varepsilon=\arctan \left(\frac{Z_{B} \tan (\theta)}{Z_{D}-\left(Z_{B}-Z_{D}\right) \tan ^{2}(\theta)}\right)
$$

where

$$
\tan (\theta)=\frac{\Delta^{\prime}}{Z_{B}}=\frac{\Delta}{f}
$$

\section{EXPERIMENT}

\section{A. Repeat measurement tests on angle of attack}

The experimental facility is $2 \mathrm{~m}$ supersonic wind tunnel of CARDC. Two cameras with 4,000,000 pixels, two computers to acquire images and two $35 \mathrm{~mm}$ fixed focus lens are used to set up a videogrammetric system. Table 1 shows the measured results at the given supporters' angles, the largest standard deviation of the measured angles of attack is $0.0075^{\circ}$; the differences of elastic angle measured by videogrammetry compared with that computed by balance are in the last column, where the biggest is $-0.0256^{\circ}$ and the smallest is $-0.0119^{\circ}$. The differences are caused by the measuring basis, because the videogrammetric basis and the elastic angle calibration of

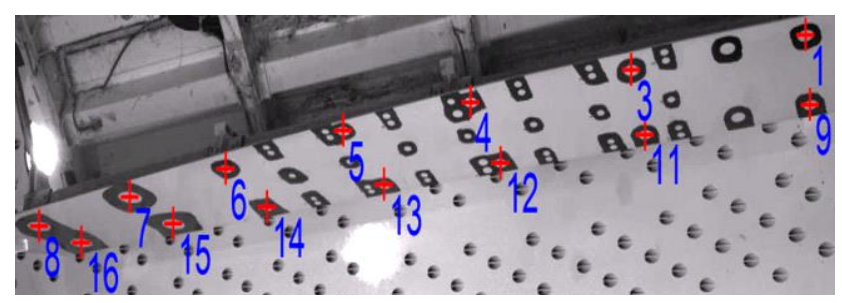

Figure 2. mark points on the full size embedded door

TABLE II. DYNAMIC DEFORMATION DATA OF THE FIRST POINT

\begin{tabular}{|c|c|c|c|c|}
\hline & 1 & 2 & 3 & 4 \\
\hline Sample frequency $(\mathrm{Hz})$ & 80 & 80 & 80 & 80 \\
\hline Number of samples & 600 & 1200 & 360 & 320 \\
\hline Average $(\mathrm{mm})$ & 5.120 & 5.246 & 5.348 & 5.215 \\
\hline Dynamic uncertainty $(\mathrm{mm})$ & 0.084 & 0.079 & 0.075 & 0.060 \\
\hline
\end{tabular}

\begin{tabular}{|c|c|c|c|c|c|c|c|c|}
\hline \multirow{2}{*}{$\begin{array}{l}\text { Angle of } \\
\text { supporter } \\
\text { (degree) }\end{array}$} & \multicolumn{5}{|c|}{$\begin{array}{l}5 \text { repeated test to measure angles of attack with } \\
\text { videogrammetry }\end{array}$} & \multirow{2}{*}{$\begin{array}{l}\text { Average } \\
\text { Value } \\
\text { (degree) }\end{array}$} & \multirow{2}{*}{$\begin{array}{l}\text { Standard deviation } \\
\text { (degree) }\end{array}$} & \multirow{2}{*}{$\begin{array}{l}\text { Differences of } \\
\text { elastic angle } \\
\text { (degree) }\end{array}$} \\
\hline & 1 & 2 & 3 & 4 & 5 & & & \\
\hline-8 & -8.2752 & -8.2868 & -8.2823 & -8.2883 & -8.2820 & -8.2829 & 0.0051 & -0.0256 \\
\hline-6 & -6.1996 & -6.2017 & -6.1995 & -6.2051 & -6.1995 & -6.2011 & 0.0024 & -0.0270 \\
\hline-4 & -4.1167 & -4.1191 & -4.1156 & -4.1213 & -4.1189 & -4.1183 & 0.0022 & -0.0220 \\
\hline-2 & -2.0385 & -2.0375 & -2.0323 & -2.0402 & -2.0351 & -2.0367 & 0.0031 & -0.0175 \\
\hline 0 & 0.0493 & 0.0507 & 0.0555 & 0.0471 & 0.0524 & 0.0510 & 0.0032 & -0.0149 \\
\hline 2 & 2.1500 & 2.1514 & 2.1568 & 2.1462 & 2.1496 & 2.1508 & 0.0039 & -0.0130 \\
\hline 4 & 4.2642 & 4.2584 & 4.2626 & 4.2526 & 4.2590 & 4.2594 & 0.0045 & -0.0161 \\
\hline 6 & 6.4004 & 6.3942 & 6.4008 & 6.3896 & 6.3964 & 6.3963 & 0.0047 & -0.0128 \\
\hline 8 & 8.5452 & 8.5481 & 8.5591 & 8.5410 & 8.5559 & 8.5499 & 0.0075 & -0.0119 \\
\hline
\end{tabular}

balance are used the digital clinometers whose precision is $0.01^{\circ}$, thus the higher precision clinometers can be

TABLE I. MEASURED RESULTS OF ANGLES OF ATTACK IN 5 REPEATED TESTS 
employed to decrease the differences.

\section{B. Dynamic deformation measurement}

The facility is $2.4 \mathrm{~m}$ transonic wind tunnel of CARDC. Fig .2 shows the positions of the mark points. The measured results of the 4 repeated tests are shown in table2, the standard uncertainty of the deformation at point 1 is $5.232 \pm 0.082 \mathrm{~mm}$, which indicates the precision of this videogrammetric system is good.

\section{Aero-optics effects measurement}

The facility is $2 \mathrm{~m}$ supersonic wind tunnel of CARDC. Fig .3 shows the OPD fields measured by videogrammetric method presented in this paper at $\mathrm{Ma}=3.0$. Fig .4 shows the measured OPD fields described by Zernike polynomial at $\mathrm{Ma}=3.0$. Fig .5 is a deflection displacement vector field
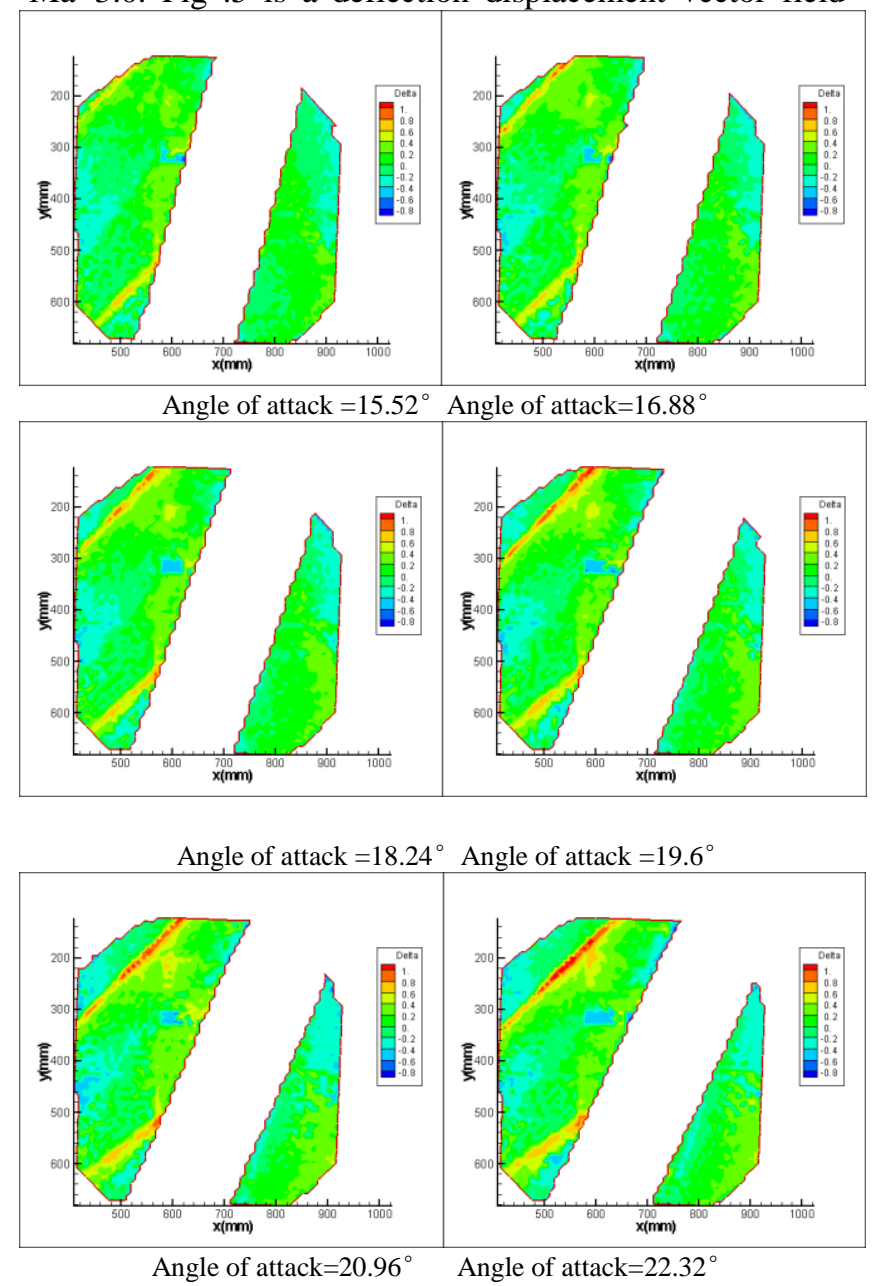

Figure 3. Measured OPD with Changing Angle of Attack

generated by the airflow of an electric drier.

\section{CONCLUSION}

The repeated tests have demonstrated the precision of the videogrammetry is good. The standard deviation of the videogrammetric angle of attack is $\leqslant 0.0075^{\circ}$; the standard uncertainty of the videogrammetric deformation data is $5.232 \pm 0.082 \mathrm{~mm}$. On the other hand, videogrammetric measurement provides a new way to research and measure aero-optic effects, which is simple and need not expensive coherent optic source. Therefore, the applications of videogrammetric measurement are big in the wind tunnel fine testing.

\section{ACKNOWLEDGMENT}

This study is supported by National Nature Science Foundation of China (Granted Number 51475453 and 11472297).
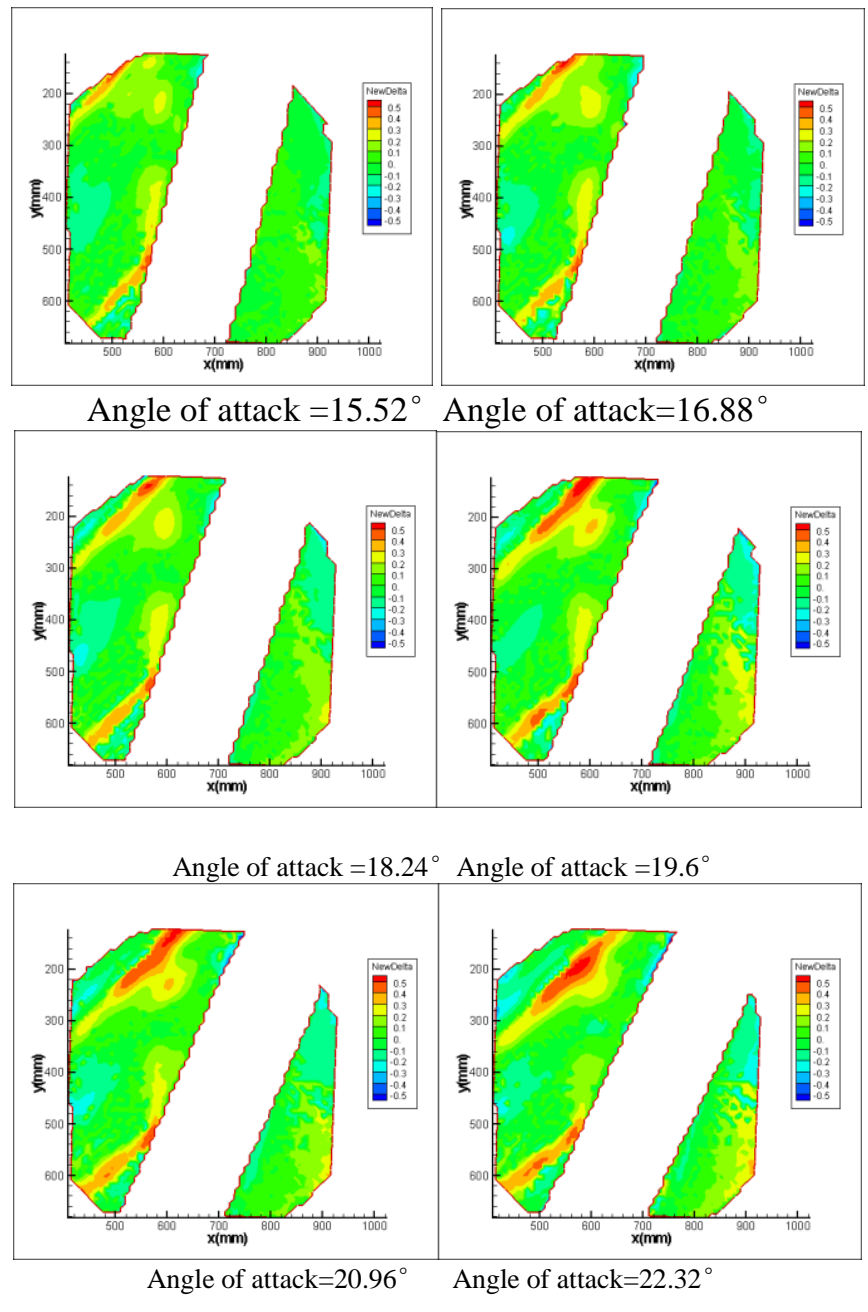

Figure 4. OPD described by Zernike polynomial

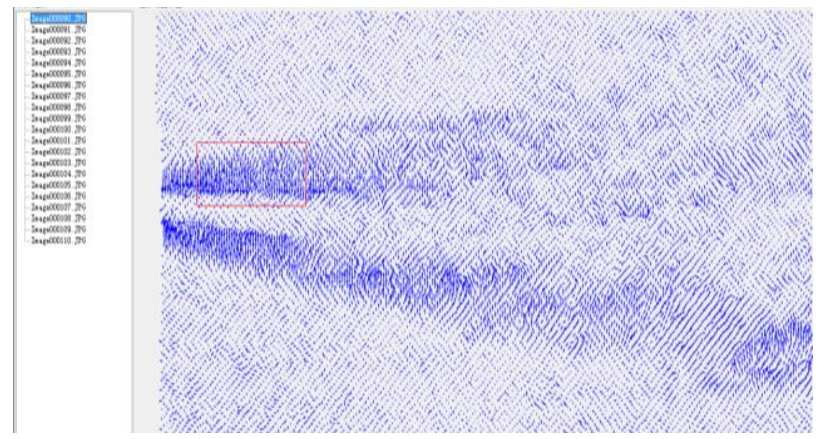

\section{REFERENCES}

[1] DANNY A B. Videogrammetric model deformation measurement technique for wind tunnel applications[R], AIAA Paper 2007-1163.

[2] LIU T, BURNER A W, PAPPA R. Photogrammetric techniques for aerospace applications[R], AIAA Press 2008. 
[3] Zhao Tao, Zhang Zhengyu. Measurement and Reconstruction for Large Aero-Optics Wavefront Distortion Field [J]. ACTA OPTICA SINICA，2013(33)10:10120031- 10120037

[4] Zheng Yu Zhang, Shui Liang Wang. Videogrammetric measurement for model displacement in wind tunnel test [J]. Applied Mechanics and Materials, 2011, (130-134):103-107

[5] Thomas W. Jones, Charles B. Lunsford. Design and Development of a Real-Time Model Attitude Measurement System for Hypersonic Facilities. 43rd AIAA Aerospace Sciences Meeting and Exhibit 10-13 January 2005, Reno, Nevada, AIAA 2005-1411

[6] SUN Yan, Zhang Zhengyu. Vision Measurement Technology Research for Model Angle of Attack in Wind Tunnel Tests. Acta Aeronautica et Astronautica Sinica, 2013, (34):1-7

[7] Luo C, Zhang Z Y. Exterior orientation for videogrammetric model deformation measurement. Journal of Experiments in Fluid Mechanics, 2010, 24(6): 88-91.
[8] Zhang Z Y, Luo C. Experimental investigation on exterio orientation in vibration environment. Journal of Experiments in Fluid Mechanics, 2011, 25(3):56-59.

[9] Zhang Z Y. Precision investigation on model displacement videogrammetric measurement in $2.4 \mathrm{~m}$ transonic wind tunnel. Journal of Experiments in Fluid Mechanics, 2011(25):56-60

[10] Zhang zhengyu. Nonlinear Distortion Correction of CameraBased on Coplanar Condition Equations[J]. Acta Optica Sinica, Vol. 32(2012): 0115002-1- 0115002-6

[11] ZHANG Zhengyu,Huang Xuhui,Yin Jiang. Measurement and Visualization of Large Aero-optics Wavefront Distortion Field in Wind Tunnel Testing, Applied Mechanics and Materials Vo1. 389 (2013) pp 1053-1057

[12] Ahmed M, Farag A. Nonmetric calibration of camera lens distortion: Differential methods and robust estimation [J]. IEEE Transactions on Image Processing, 2005, 14 (8):1215 1230. 